\title{
Thresholds of schizophrenics to sinusoidal electrical vestibular stimulation"
}

\author{
Ernest Dzendolet, UNIVERSITY OF MASSACHUSETTS \\ Thomas J. Moore, UNIVERSITY OF MASSACHUSETTS AND NORTHAMPTON VA HOSPITAL
}

\begin{abstract}
The mean electrical vestibular threshold of schizophrenics was significantly higher at $0.50 \mathrm{cps}$ than that of normals. Individual electrical vestibulograms could be divided into three groups, those with peaks at 0.50 , at 0.20 , and at 0.50 and $2.0 \mathrm{cps}$, including 12,4 , and 2 patients, respectively. The first two patterns appear specifically schizophrenic.
\end{abstract}

\section{Problem}

A number of investigations, e.g., Leach (1960), and also summaries, e.g., Meehl (1962), have reported that schizophrenics show a lessened reactivity to caloric and rotational vestibular stimulation. We decided to see if a similar lessened reactivity occurred with sinusoidal electrical stimulation, using a new technique for determining absolute thresholds which did not depend on S's report (Dzendolet, 1963).

\section{Method}

Ss were 20 male patients who had a clinical diagnosis of schizophrenia, and were indicated by their therapist or ward physician as being cooperative. ${ }^{2}$ No differentiation was made between subtypes in selecting these patients. Further restrictions were that none were to have a history of either an inner ear, or other neurological disorder, and if they were on any medication, that it be chloropromazine because it has been reported as ineffective in treating vestibular disorders (Smith, 1958,p.322), and did not affect vestibular reflexes to caloric and rotational stimuli in the rabbit (Jonkees \& Philipzoon, 1960). A related compound, prochlorperazine, on the other hand, has been effectively used in vestibular disorders. Two patients were not on any medication, one for a week and the other for a month before their first experimental session. Participation in this experiment was voluntary and the patient could refuse to continue at any time. Ss' ages ranged from 27 to $54 \mathrm{yr}$., with 12 being under 40 and three, 50 or over, the median being 38 . Continuous hospitalization periods ranged from $5 \mathrm{mo}$. to $17 \mathrm{yr}$., the median being $4 \mathrm{yr}$. The criteria used to calculate the periods were if less than $2 \mathrm{yr}$. had elapsed between discharge and readmission, the date of first admission was used. If more than $2 \mathrm{yr}$. had elapsed since discharge, readmission date was used. One yr. after these data were collected, 14 patients had been discharged, two of whom were subsequently readmitted.

S's sway was measured by a lever lastened to the wiper of a "minitorque" potentiometer. The lever was fastened in turn to the top of an Army helmet liner worn by S. The potentiometer itself was mounted on bearings and attached to a framework so that only sideways movements of $\mathrm{S}$ moved the wiper. The potentiometer was connected as a voltage divider and its output was displayed on the first channel of a dual channel linearly writing oscillograph. $\mathrm{Ag}-\mathrm{AgCl}$ fluid electrodes were placed on S's mastoid processes, and sinusoidal electrical stimuli of $0.030,0.050,0.10,0.20,0.50,1.0,2.0$, and 4.0 cycles per second (cps) were applied in random order between the electrodes for one presentation at each frequency on each of two sessions held on separate days. The stimulus generator, S and second channel of the dual oscillograph were connected in series so that the current which passed through $\mathrm{S}$ was recorded. The stimulus amplitude was always increased from below threshold, slowly and linearly by means of a motor drive attached to the gain control of the stimulus generator, until either $\mathrm{S}$ complained of prickling at the electrode site, or an amplitude of $3.5 \mathrm{ma}$ had been reached. At this time the stimulus was immediately turned off. The Ss wore earplugs, and also had earphones on his helmet liner through which white masking noise was introduced, giving a net level of about $30 \mathrm{db}$ above absolute threshold, an amount not considered sufficient to stimulate the vestibular apparatus directly (Bekesy, 1935). Ss were instructed that sway under conditions of noise was being investigated and that we might cause him to sway occasionally, but that he should remain relaxed throughout the session.

To determine the absolute threshold (RL), S's peak-to-peak sway amplitude in each 5-sec. interval of the record was measured, a three-term moving average of these amplitudes computed and assigned to the mid-term of the average. If any average were twice the value of the amplitude of the term just before those in the average, and if that average and the next two were monotonic increasing, then an objective RL existed and was assigned to the term just before those in the average. The peak amplitude of the stimulus in ma corresponding to the mid-point of the RL interval was the RL for that trial.

\section{Results}

The mean electrical vestibulogram for the 20 schizophrenics is shown in Fig. 1 with that of 20 normal college students who ranged in age from 18 to $27 \mathrm{yr}$. with a median of $22 \mathrm{yr}$. Data for the latter group were obtained from an earlier study on 19 subjects (Dunstone \& Dzendolet, 1964), combined with data of one randomly selected S from a still earlier study (Dzendolet, 1963). A two-factor design with repeated measures on one factor (Winer, 1962, p. 302) showed the schizophrnics versus normals main effect to be significant $(p<.005)$. Although eight frequencies were used in the investigation, the two lowest frequencies, 0.030 and $0.050 \mathrm{cps}$, were not included in the analysis because of missing data at these frequencies in the normal group. Subsequent $F$ tests between the schizophrenic and normal thresholds at each frequency indicated that the only frequency at which a significant difference in mean thresholds existed was at $0.50 \mathrm{cps}$, at which the

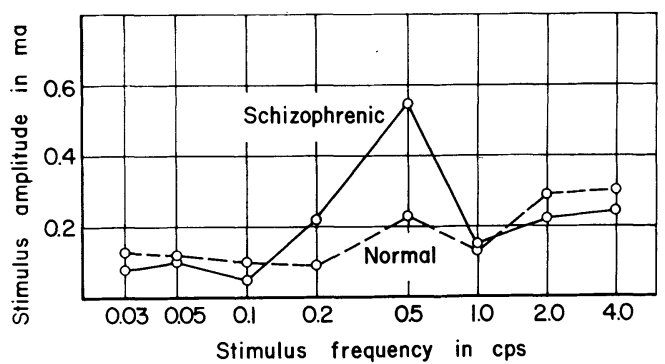

Fig. 1. Mean electrical vestibulograms of hospitalized schizophrenic patients and of normal Ss. The electrical vestibulogram is a plot against stimulus frequency of objectively determined thresholds for a lateral swaying response in standing Ss to low frequency sinusoidal electrical currents passed between their mastoid processes. The difference in peaks at $0.50 \mathrm{cps}$ is statistically significant $(p<.005)$. 
schizophrenics' mean threshold was significantly higher than that of the normals' $(p<.001)$.

In an earlier study (Dunstone \& Dzendolet, 1964), it had been shown that electrical vestibulograms of normal Ss can be grouped into six types, four of which account for $87.5 \%$ of the Ss. The grouping was based on certain criteria applied visually to individual vestibulograms, with the validity for such a separation supported by a factor analysis. Mean values of the different normal types are shown in Fig. 2. A similar visual separation was carried out on the schizophrenic vestibulograms, but on only 18 of the 20 Ss because two of them had one missing threshold value each. Of the 18,12 showed the large rise in threshold at $0.50 \mathrm{cps}$ as in the mean curve (Fig. 1). Four differed in that they had peaks at 0.20 rather than $0.50 \mathrm{cps}$, and possibly another at $2.0 \mathrm{cps}$; the remaining two Ss had peaks at both 0.50 and $2.0 \mathrm{cps}$. The high RL at $2.0 \mathrm{cps}$ was due primarily to one $\mathrm{S}$. Mean values of these three groups are shown in Fig. 3, Group A peaking at $0.50 \mathrm{cps}$, Group B at $0.20 \mathrm{cps}$, and Group $C$ at 0.50 and $2.0 \mathrm{cps}$. Both Ss who were not on medication fell into Group A. The peak at $2.0 \mathrm{cps}$ in Group B is probably not significant because it occurs primarily with only one of the four Ss.

\section{Diseussion}

These data show that the reported lessened vestibular reactivity of schizophrenics also occurs with electrical stimulation. In addition, the lessened reactivity is very specific, occurring primarily at $0.50 \mathrm{cps}$. Comparison of the schizophrenic vestibulograms with those in Fig. 2 shows that Group A did not occur in the normal sample, but that Group B schizophrenics may be the same as the Type 5 normals. Ther percentage occurrence of the latter vestibulogram is very different in the normal and schizophrenic samples tested, being a little over $6 \%$ with the normals, and about $22 \%$ with the schizophrenics. Group $\mathrm{C}$ resembles the Type 3 normals, but the dif-

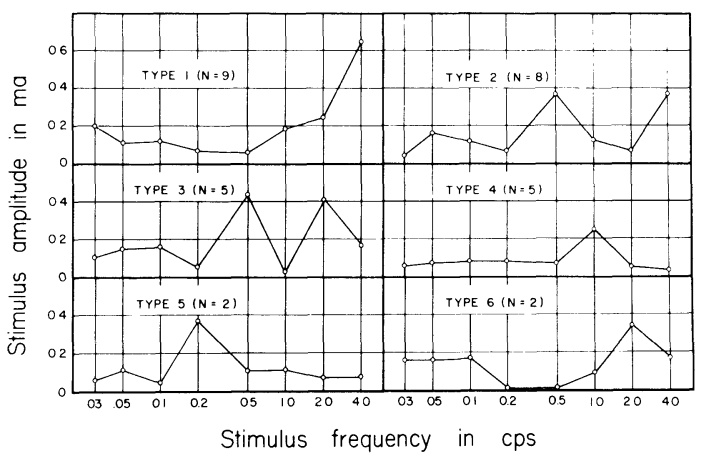

Fig. 2. Mean vestibulograms obtained after sorting those of individuals according to the following criteria: (1) a maximum at 4.0 cps, (2) peaks at 0.50 and $4.0 \mathrm{cps}$, (3) peaks at 0.50 and $2.0 \mathrm{cps}$, (4) a maximum at $1.0 \mathrm{cps}$, (5) a maximum at $0.20 \mathrm{cps}$, and (6) a maximum at $2.0 \mathrm{cps}$. N refers to the number of subjects who fell into each type. From Dunstone \& Dzendolet (1964), reproduced by permission.

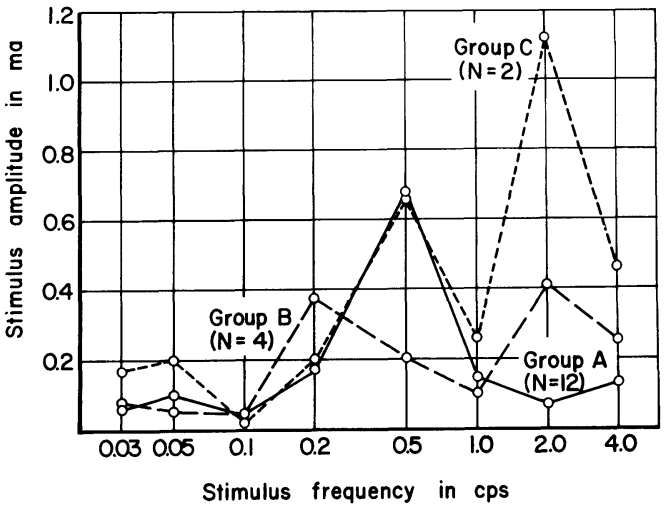

Fig. 3. Mean curves obtained by visually sorting individual vestibulograms of hospitalized schizophrenics into those with a peak at $0.50 \mathrm{cps}$, at $0.20 \mathrm{cps}$, and at 0.50 and $2.0 \mathrm{cps}$. Only the first two, Group A and Group B, are considered schizophrenic patterns. $\mathrm{N}$ is number of patients in each group.

ference in percentage of occurrence is opposite to the Group B-Type 5, in that the Group C-Type 3 vestibulogram occurs in about $16 \%$ of the normals and about $6 \%$ of the schizophrenics. These data suggest that the Group $A$ and $B$ vestibulograms are specific to schizophrenics because there is little or no overlap with normal patterns, but that Group $\mathrm{C}$ is not because of its limited occurrence in these patients.

Examination of the hospital records of the patients did not indicate any behavioral or other differences between them, e.g., type of schizophrenia, age, height and weight, which would be correlated with their giving either Group A or Group B vestibulograms. Their scores on the Phillip's Scale of Pre-Morbidity (Phillips, 1953) showed that both Good and Poor Pre-Morbids were about equally represented in the groups.

\section{References}

BEKESY, G. v. Ueber akustische Reizung des Vestibularapparates. pflueg. Arch. ges. Physiol., 1935, 236, 59-76.

DUNSTONE, J. J., \& DZENDOLET, E. Types of electrical vestibulograms. Percep. mot. Skills, 1964, 19, 899-904.

DZENDOLET, E. Sinusoidal electrical stimulation of the human vestibular apparatus. Percep. mot. Skills, 1963, 17, 171-185.

JONKEES, L. B., \& PHILIPZOON, A. J. Some nystagmographical methods for the investigation of the effects of drugs upon the labyrinth. Acta Physiol. Pharmacol. Neerl., 1960, 9, 240-275.

LEACH, W. Nystagmus: An integrative neural deficit in schizophrenia. J. abnorm. soc. Psychol., 1960, 60, 305-309.

MEEHL, P. F. Schizotaxia, schizotypy, schizophrenia. Amer. Psychologist, 1962, 17, 827-838.

PHILLIPS, L. Case history and prognosis in schizophrenia. J. nerv. ment. Dis., 1953, 117, 515-525.

SMITH, P. Drugs of choice, 1958-1959. St. Louis: C. V. Mosby, 1958. WINER, B. J. Statistical principles in experimental design. New York: McGraw-Hill, 1962.

\section{Notes}

1. This investigation was supported in part by Public Health Research Grant NB-03675-03 from the National Institute of Neurological Diseases and Blindness.

2. All patients were tested at the Northampton Veterans Administration Hospital, Northampton, Massachusetts. 